\title{
Editorial
}

\section{WHAT ABOUT RESIDUES FROM CIRCULAR ECONOMY AND ROLE OF LANDFILLING?}

The current European policy for waste management is based on the concept of Circular Economy, intended as a global strategy consisting in a set of actions aimed at maintaining the value of the products over a longer period, saving non-renewable resources and minimising waste generation.

The emphasis placed subsequently on the recycling of waste has promoted throughout Europe a marked increase of separate collection, often perceived by politicians and citizens as the definitive solution for any waste disposal problem.

Consequently, the hierarchical waste management strategy (Prevention, Reuse, Recycling, Energy recovery, Landfilling) has frequently been approached in moral and demagogic terms rather than in technical terms, and the bad boys of waste management technologies, (i.e. incineration and landfilling) have been blacklisted as the forbearers of all evils, often being deemed superfluous.

In particular, landfilling has been banished as a hazardous system, obsolete and polluting, as strongly underlined on both a political and regulatory level.

This emphasis has resulted in the underestimation of a series of aspects that are currently emerging quite dramatically:

- not all wastes produced can be disposed of by means of separate collection and recycling;

- wastes cannot be recirculated endlessly;

- recycling activities in turn generate residues and wastes, even in the unlikely hypothesis of separate collection achieving a $100 \%$ rate;

- hazardous substances contained in the original products accumulate in the recycled materials posing risks for human health during their use and for the environment in case of uncontrolled disposal;

- the negative perception of landfills and incineration, largely stoked also by the communication strategies of the European Union, has fostered a non-acceptance amongst public opinion that today has turned heavily against the administrators attempting to establish the necessary facilities;

- although viewing landfills as an obsolete system to be abandoned, nothing has been done to date on a regulatory level to promote sustainability of the system and allow it to act as a virtuous sink to close the material loop and immobilize the abovementioned contaminants.
Recycling processes, in the same way as procedures used in the processing of natural resources, can be outlined in four distinct stages: extraction, selection, refinement and production (Figure 1).

Each of these stages produces residues that will subsequently need to undergo treatment in order to render innocuous or immobilise potential contaminants; lastly, a final sink will need to be identified in which to store the wastes safely and sustainably over an extended period of time, as is the case with any type of natural cycle.

On the basis of the flow chart provided in Figure 1, the total amount of waste/residue generated $\left(R_{\text {tot }}\right)$ is thus obtained from the difference between the diverse waste flows (Wi) and the final products (Ph), as described by the following mass balance equation:

$R_{\mathrm{tot}}=\sum_{i, j, k, h}\left(R_{i}+R_{i, j}+R_{i, j, k}+R_{i, j, k, h}\right)=\sum_{i} W_{i}-\sum_{h} P_{h}$

The amounts of residues, where they are generated and how they are treated and disposed of are clearly evident from the official statistical waste management data available for different countries.

Indeed, data routinely communicated relate to the quantities and percentages of wastes which, downstream of collection, are forwarded to the three main treatment options - recycling, thermal treatment and landfilling, whilst

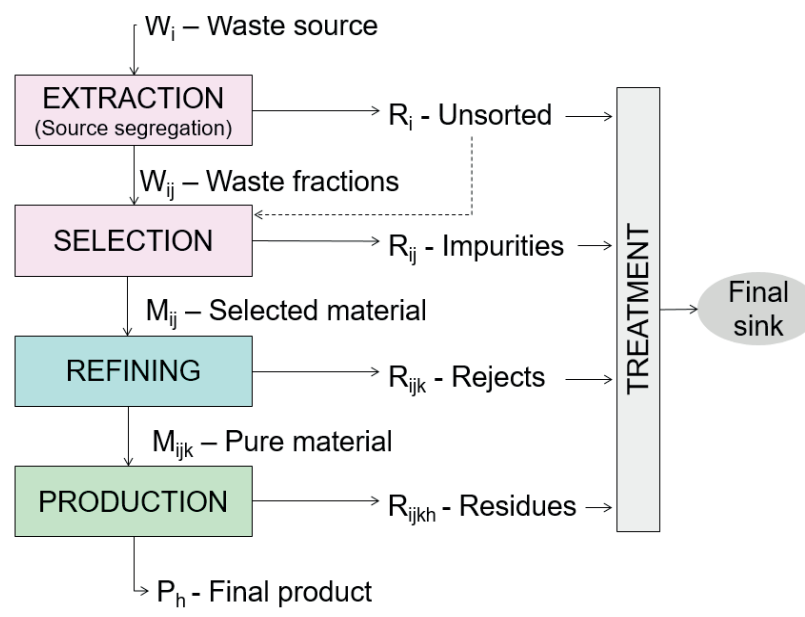

FIGURE 1: Recycling processes and related flows of materials (W: Waste, M: Valuable materials, R: Residues, P: Products) (i: different waste source, $\mathrm{j}$ : individual recovered fraction, $\mathrm{k}$ : pure materials from the individual recovered fraction, h: individual type of product). 
ignoring the disposal flows of treated waste. This however is misleading as it masks the effective use of both landfills and incineration. As an example, countries such as Germany, the Netherlands, Denmark and Japan would seem to have more or less eliminated the use of landfills, reducing this to a mere $2-3 \%$, thereby endorsing the idea amongst the public in other countries that landfilling is superfluous.

Likewise, inclusion of the production of SRF (Solid Recovered Fuel) or RDF (Refuse Derived Fuel) in recycling conceals the fact that most of these materials ultimately end up in thermal treatment plants, while some are co-fired in other facilities (coal power plants, cement plants, etc.).

The entire international scenario would therefore be better represented by taking into account the actual disposal of wastes.

Indeed, considering how disposal represents the action or process of getting rid of something, the disposal of waste is actually achieved through the production of end products in recycling, together with gasification of material in thermal treatment and permanent depositing in landfilling.

Consequently, statistical data available worldwide should be updated to take into consideration residues originating from different treatment options (recycling, thermal treatment, landfilling) and the disposal routes according to mass balance flows schematised in Figure 2.

The following assumptions are made here in:

- only $60 \%$ of the recovered waste fractions become new products (as average considering the different materials);

- at least $20 \%$ of residues from the processing of recovered waste fractions are sent to thermal treatment;

- $20 \%$ of the residues from recycling processes are landfilled;

- the total amount of solid residues from thermal treatment ranges around $30 \%$, including APC residues and fly ashes (30\%), and bottom ashes (70\%); assuming that half of bottom ashes are recycled, the disposal routes for thermal treatment residues could be calculated as $20 \%$ of total thermally treated waste to landfilling and $10 \%$ to recycling;

- no material is recovered from landfill, although using an Enhanced Landfill Mining concept this would be possible.

These assumptions are of course indicative and may vary significantly not only from one waste fraction to another but also from one country to another.

By implementing these assumptions in the statistical datasets describing waste management in different countries a situation diverse from that commonly represented is described. This is clearly evident from Figure 3 , where the two different situations are represented using the triangular chart originally proposed by Cossu (2009).

Specifically, Figure 2A illustrates the percentage of use of the different treatment methods based on statistical data provided by The World Bank (2018) according to mass balance boundary A of Figure 2. Figure 2B provides actual disposal rates calculated according to the assumptions described in Figure 2 (mass balance boundary B).

Analysing the two graphs the following concluding remarks can be drawn:

- considerable amounts of residues are produced throughout the different recycling processes, including products which cannot be further recycled for technical or environmental reasons (accumulation of contaminants); these residues need a secure final sink in order to avoid diffuse pollution;

- landfilling plays a much higher crucial role in waste management strategy than generally recognised by authorities;

thermal treatment represents an important option in countries with a high population density, where it is conveniently coupled with Circular Economy actions;

- "zero waste" (ZW) appears an even more unrealistic proposal, and can be considered solely when viewed as a conceptual trend;

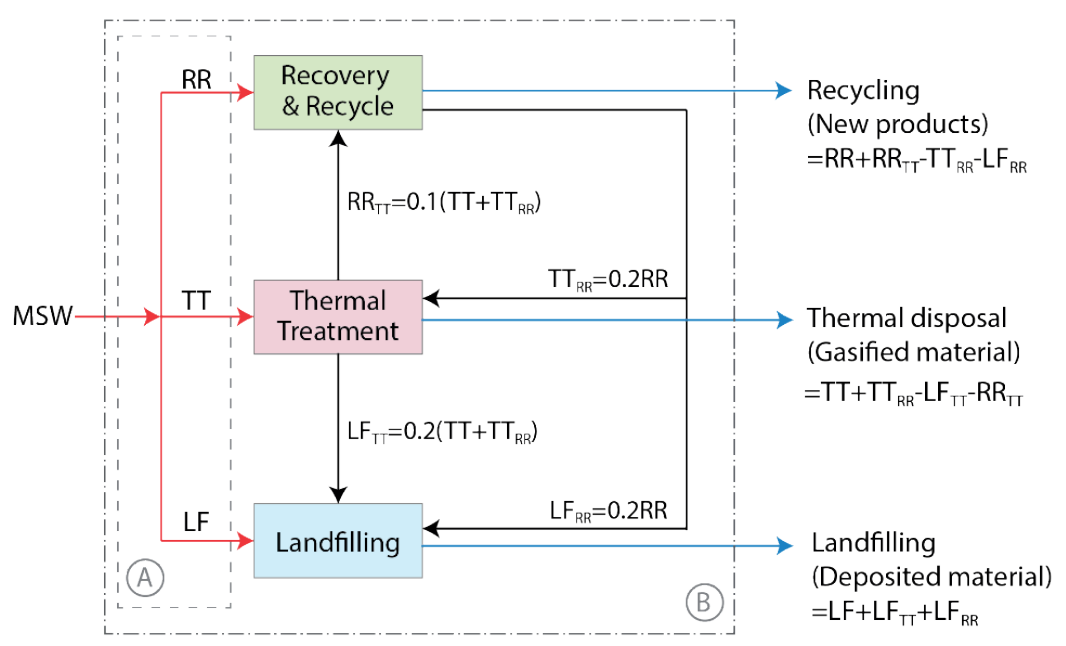

FIGURE 2: Mass balance flows of a Municipal Solid Waste (MSW) system, considering two different boundaries: A=waste treatment; $\mathrm{B}=$ waste disposal. (MSW: Amount of handled waste; RR, TT, LF: Amount of waste sent respectively to Recovery and Recycle, Thermal Treatment and Landfilling; TTRR, LFRR: Amount of residues (\% by weight) from Recycling sent respectively to Thermal Treatment and Landfilling; RRTT, LFTT: Amount of residues (\% by weight) from Thermal Treatment which are sent respectively to Recycling and Landfilling). 
A

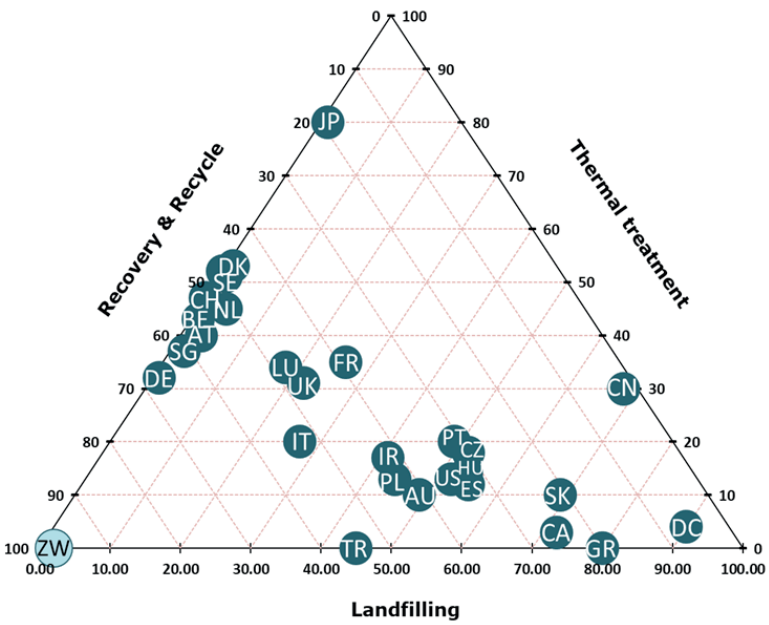

B

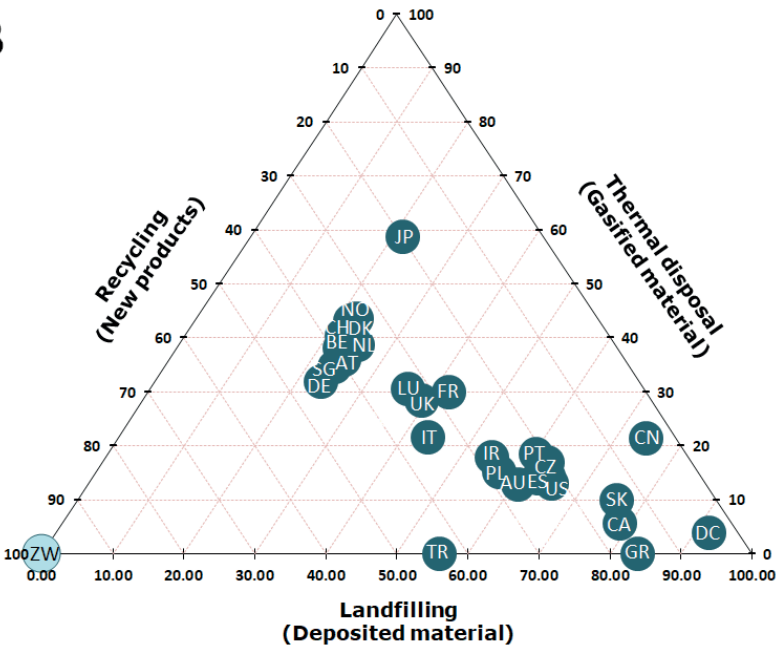

FIGURE 3: Graphical representation of the scenario of municipal solid waste management throughout the world arranged according to the three main options of treatment and disposal using the triangular chart proposed by Cossu (2009). Countries have been indicated using their e-mail country codes. DC = Developing Countries; ZW = Zero Waste. Chart A represents data derived from The World Bank (2018), Chart B describes the situation based on actual disposal rates, calculated according to assumptions described in Figure 2.

- landfilling terminology should be defined in order to differentiate the wide range of technological applications and quality of accepted waste (untreated waste, mechanical-biological pre-treatment, predominantly inorganic waste, etc);

- landfilling should be conceptually and technically remodelled in order to fulfil the fundamental strategic role of acting as a sink in Circular Economy strategies; this should be reflected in a new set of landfill regulations.

Some of the abovementioned aspects have been recognised by the European Union, which specifies in the Directive 2018/850/EC: "In order to ensure the reliability of data, it is important to lay down more precisely the rules according to which Member States should report municipal waste that has been landfilled". However, the results of this approach are not yet evident, also due to the failure of several countries to date to implement the Directive in national regulations.

In the same Directive, the EU maintains a negative approach towards landfilling ("A progressive reduction of landfilling is necessary to prevent detrimental impacts on human health and the environment") considering it a kind of dustbin in the waste management systems lacking the role of final sink to close the material loop, which would allow the diffusion of contaminants to be kept under control (Cossu, 2016).

Raffaello Cossu *, Valentina Grossule, Maria Cristina Lavagnolo

University of Padova, Italy

* raffaello.cossu@unipd.it

\section{REFERENCES}

Cossu R. (2009) From triangles to cycles. Waste Management, 29, 2915-2917. doi:10.1016/j.wasman.2009.09.002

Cossu R. (2016) Back to Earth Sites: From "nasty and unsightly" landfilling to final sink and geological repository. Waste Management 55, 1-2, doi: 10.1016/j.wasman.2016.07.028

The World Bank, 2018. What a Waste 2.0. doi:10.1596/978-1-4648$1329-0$ 